\title{
Resistência inicial de quatro espécies arbóreas em diferentes espaçamentos após ocorrência de geada
}

\author{
Initial resistance of four arboreal species in different spacing after frost occurrence
}

\author{
Braulio Otomar Caron ${ }^{\mathrm{I}}$ Velci Queiróz de Souza ${ }^{\mathrm{II}}$ Elder Eloy $^{\mathrm{I}}$ Alexandre Behling \\ Denise Schmidt ${ }^{\mathrm{III}}$ Rômulo Trevisan ${ }^{\mathrm{IV}}$
}

\section{RESUMO}

\begin{abstract}
A ocorrência de geada, dependendo do grau de dano, pode se tornar um fator limitante para a condução de florestas de curta rotação. O presente trabalho teve como objetivo avaliar o comportamento após ocorrências de geadas das espécies florestais Acacia mearnsii De Wild, Eucalyptus grandis W. Hill ex Maiden, Mimosa scabrella Benth e Ateleia glazioveana Baill submetidas a níveis de espaçamento de 2,0x1,0m; 2,0x1,5m; 3,0x1,0 e 3,0x1,5m um ano após o plantio, na região Norte do Rio Grande do Sul. Os danos (resistência a geada) foram avaliados segundo o sistema de notas de 0 a 10, conforme a intensidade do dano na planta. Os graus de resistência à geada foram determinados em função da intensidade do dano na planta. Os níveis de espaçamento estudados não afetaram respostas das espécies em relação ao dano ocasionado por geada. A espécie Mimosa scabrella apresentou ser resistente, enquanto que Eucalyptus grandis $e$ Ateleia glazioveana, tolerantes. Já a Acacia mearnsii apresentou ser moderadamente tolerante a tolerante.
\end{abstract}

Palavras-chave: espécies florestais, tolerância ao frio, densidades de plantio.

\section{ABSTRACT}

The frost occurrence depending on the damage degree, can become a limit factor for the transport of forests of short rotation. The present research has as objective evaluate the behavior after occurrences of frosts of the species forest Acacia mearnsii De Wild, Eucalyptus grandis W. Hill ex Maiden, Mimosa scabrella Benth and Ateleia glazioveana Baill were submitted to levels of spacing of $2.0 \times 1.0 \mathrm{~m} ; 2.0 \times 1.5 \mathrm{~m} ; 3.0 \times 1.0 \mathrm{~m}$ and $3.0 \times 1.5 \mathrm{~m}$ one year after the planting, in the North of Rio Grande do Sul. The damages (resistance to frost) were appraised according to scale 0 to 10 according to the intensity of the damage in the plant. The frost resistance degrees were certain in function of the intensity of the damage in the plant. The spacing levels studied didn't affect the species answers in relation to the damage caused by frost. The species Mimosa scabrella presented to be resistant, while Eucalyptus grandis and Ateleia glazioveana tolerant. Already the Acacia mearnsii was moderately tolerant to tolerant.

Key words: forest species, tolerance to the cold, planting densities.

\section{INTRODUÇÃO}

A suscetibilidade das culturas às baixas temperaturas varia muito de acordo com a espécie e o estágio de desenvolvimento fenológico (CAMARGO et al., 1993). Por outro lado, o espaçamento entre as plantas é um dos fatores que está relacionado com os danos provocados por geada. Isso ocorre devido à radiação solar, que é interceptada através do dossel formado pela copa das árvores. Na linha de plantio, em espaçamentos menores, ocorre formação de dossel mais precocemente, quando comparado com os espaçamentos maiores. $\mathrm{O}$ dossel das plantas diminui as perdas radiativas durante a noite, como demonstrado em trabalhos conduzidos por PILAU et al. (2007).

'Departamento de Agroclimatologia, Centro de Educação Superior Norte do Rio Grande do Sul (CESNORS), Universidade Federal de Santa Maria (UFSM), 98400-000, Frederico Westphalen, RS, Brasil. E-mail: braulio.caron@pq.cnpq.br. *Autor para correspondência.

"Departamento de Melhoramento Genético de Plantas, CESNORS, UFSM, Frederico Westphalen, RS, Brasil.

"I'Departamento de Produção Vegetal, CESNORS, UFSM, Frederico Westphalen, RS, Brasil.

${ }^{\mathrm{IV}}$ Departamento de Tecnologia de Produtos Florestais, CESNORS, UFSM, Frederico Westphalen, RS, Brasil. 
O Estado do Rio Grande do Sul é caracterizado por maiores ocorrências de geadas tardias (primaveris) do que as precoces (outonais). A maior probabilidade de ocorrência de geada apresenta-se no segundo decêndio de julho (INMET, 2007). SELLE \& VUADEN (2007) ressaltaram que cinco dias de geadas na primeira quinzena de julho, resultaram em grandes danos em plantios da espécie Eucalyptus grandis, no município de Santa Maria. Nesse mesmo sentido, a ocorrência de geada, conforme seu grau de dano, pode se tornar um fator limitante para a condução de florestas de curta rotação.

Em teste de procedências e progênies de Eucalyptus viminalis Labill, aos 10 meses de idade em Chapecó - SC, FLOSS et al. (1997) observaram que 36\% das plantas foram danificadas por geadas, constatando, aos 60 meses de idade, mortalidade de $20 \%$ das plantas. HIGA et al. (1997), avaliando o comportamento de vinte espécies de Eucalyptus em Campo do Tenente - PR, observaram que Eucalyptus dunnii Maiden e Eucalyptus camaldulensis Dehnh apresentaram sobrevivência superior a $70 \%$, porém $27 \%$ das árvores remanescentes apresentaram bifurcações. Esses resultados demonstram os efeitos das geadas nos primeiros anos após o plantio.

A avaliação da resistência inicial às geadas de diferentes essências florestais permite ao silvicultor conhecer a adaptação das plantas e a interferência das geadas no crescimento e desenvolvimento das espécies, pois, como citado, essas alterações climáticas podem provocar mortalidade e danos aos plantios. Nesse sentido, este trabalho teve como objetivo avaliar, após ocorrências de geadas na região norte do Rio Grande do Sul, o comportamento inicial das espécies florestais Acacia mearnsii De Wild, Eucalyptus grandis W. Hill ex Maiden, Mimosa scabrella Benth e Ateleia glazioveana Baill submetidas a diferentes níveis de espaçamento.

\section{MATERIAL E MÉTODOS}

O trabalho foi realizado no experimento que está localizado em área pertencente ao Laboratório de Agroclimatologia, vinculado à Universidade Federal de Santa Maria, Campus CESNORS (Centro de Educação Superior Norte do Rio Grande do Sul), sob coordenadas geográficas de $27^{\circ} 22^{\prime \prime} \mathrm{S} ; 5^{\circ} 25^{\prime \prime} \mathrm{W}$, a $480 \mathrm{~m}$ de altitude, no município de Frederico Westphalen RS.

Segundo a classificação climática de Köppen, o clima da região é Cfa, ou seja, subtropical úmido com temperatura média anual de $19,1^{\circ} \mathrm{C}$, variando com máxima de 38 e mínimo de $0^{\circ} \mathrm{C}$. De acordo com
ARAÚJO (1930), Frederico Westphalen encontra-se na região climática do Alto Vale do Uruguai. Iraí, distante aproximadamente $30 \mathrm{~km}$ de Frederico Westphalen, é o município tomado como referência para os dados de classificação climática. Conforme proposta de MALUF (2000), Iraí apresenta clima de tipo subtemperado subúmido, sendo a temperatura média anual de $18,8^{\circ} \mathrm{C}$ e temperatura média do mês mais frio de $13,3^{\circ} \mathrm{C}$.

$\mathrm{O}$ experimento foi instalado utilizando o delineamento experimental de blocos completos casualizados em três repetições, caracterizados por um fatorial $4 \mathrm{x} 4$, ou seja, quatro espaçamentos $(2,0 \times 1,0 \mathrm{~m}$, $2,0 \times 1,5 \mathrm{~m}, 3,0 \mathrm{x} 1,0 \mathrm{~m}$ e $3,0 \mathrm{x} 1,5 \mathrm{~m})$ e as quatro espécies florestais. O bloco contempla 16 unidades experimentais, sendo que cada uma destas possuem 45 plantas distribuídas em cinco linhas.

Os danos (resistência a geada) foram avaliados segundo o sistema de notas utilizado por HIGA et al. (2000). Nesse sistema, atribuiu-se uma nota de 0 a 10 para cada planta (Tabela 1). Para atribuição dos graus de resistência à geada, adaptou-se metodologia utilizada por CARVALHO (1981). Para a espécie Ateleia glazioveana, os danos foram computados somente no caule, devido à senescência das folhas ter iniciado antecipadamente ao período da ocorrência da geada.

A ocorrência de geada foi observada nos dias 2 e 3 de junho e 3, 24, 25, 26 e 29 de julho de 2009 (onze meses após o plantio). Antes de ocorrer a primeira geada foi realizada a avaliação da altura das árvores (HA - altura antes da geada). Após 30 dias da ocorrência da última geada, avaliaram-se os danos causados à parte aérea do vegetal e altura das plantas (HD - altura depois da ocorrência da geada) que sofreram danos. Após 100 dias da ocorrência de geada, avaliou-se a porcentagem de sobrevivência das plantas.

A altura foi medida com auxílio de régua graduada em centímetros. As notas dos danos foliares foram atribuídas visualmente e as do caule através do cálculo de porcentagem com base nos dados das alturas HA e HD através do emprego da seguinte equação:

$\%$ de dano no caule $=(100-(\mathrm{HDx} 100 / \mathrm{HA})$. A porcentagem de sobrevivência (\% sobrev) das plantas foi calculada com base no número de plantas vivas antes da ocorrência de geada (AG) e depois da ocorrência de geada (DG) pela equação: \% sobrev = (DGx100)/AG

Os valores de temperatura foram obtidos da Estação Climatológica do INMET (Instituto Nacional de Meteorologia), vinculada ao Laboratório de Agroclimatologia do Departamento de Agronomia do CESNORS. A estação situa-se cerca de $500 \mathrm{~m}$ do experimento sob coordenadas $27,3956^{\circ} \mathrm{S}$ e $53,4294^{\circ} \mathrm{W}$. 
Tabela 1 - Notas atribuídas aos danos causados por geadas e graus de resistência à geada, no município de Frederico Westphalen - RS.

\begin{tabular}{lll}
\hline Nota & \multicolumn{1}{c}{ Nível de dano* } & Grau de resistência \\
\hline 10 & Sem dano visual & Resistente \\
9 & Menos de $25 \%$ da área foliar danificada & Tolerante \\
8 & $25-49 \%$ da área foliar danificada & Tolerante \\
7 & $50-74 \%$ da área foliar danificada & Tolerante \\
6 & $75-99 \%$ da área foliar danificada & Tolerante \\
5 & $100 \%$ da área foliar danificada & Tolerante \\
4 & Menos de $25 \%$ do caule danificado & Moderadamente tolerante \\
2 & $25-49 \%$ do caule danificado & Sensível \\
1 & $50-74 \%$ do caule danificado & Muito sensível \\
0 & $75-99 \%$ do caule danificado & Muito sensível \\
\hline
\end{tabular}

Fonte: Adaptado de CARVALHO \& COSTA (1981) e HIGA et al. (2000).

*As notas inferiores a 5 apresentavam $100 \%$ da área foliar queimada.

Os dados obtidos a campo foram submetidos à análise estatística com o uso do software SAS Learning Edition 8.0 (2003). Foram testadas as pressuposiçõos da análise de variância (normalidade) e identificou-se qual o fator de correção que melhor as atendeu. Assim, foram transformadas as notas dos danos de geada na folha em $x^{2}$. Após, foram realizadas a análise de variância e o teste de Tukey a $5 \%$ de probabilidade.

\section{RESULTADOS E DISCUSSÃO}

A ocorrência de geada no experimento foi observada nos dias 2 e 3 do mês de junho, nos quais se observaram temperaturas de 4,8 e $-0,6^{\circ} \mathrm{C}$, respectivamente, e, nos dias 3, 24, 25, 26 e 29 de julho de 2009, observaram-se as temperaturas: $6 ;-2,2 ;-2,7$; 0,5 e $7,8^{\circ} \mathrm{C}$, respectivamente. A diferença entre a temperatura medida no abrigo meteorológico $(1,5 \mathrm{~m})$ e a medida na relva varia de $3,3^{\circ} \mathrm{C}$ (SILVA \& SENTELHAS, 2001) a $7^{\circ} \mathrm{C}$ (GRODZKI et al., 1996). Considerando tal diferença entre a temperatura de relva e do abrigo meteorológico, é provável que a temperatura mínima absoluta possa ter atingido valores inferiores aos observados.

Deve-se destacar a ocorrência das duas geadas no mês de junho, ainda na estação de outono, que, de acordo com MOTA (1975), as geadas ocorridas nesta época podem ser classificadas como outonais. Segundo CAMARGO et al. (1993), temperaturas medidas no abrigo meteorológico abaixo de $3{ }^{\circ} \mathrm{C}$ já causam danos às plantas. Nesse período, conforme MOTA(1975); PEREIRA et al. (2001), são ocasionados os maiores danos, devido à atividade vegetativa existente e por atingirem as plantas pouco rustificadas.

As espécies tiveram diferentes comportamentos face à ocorrência de geadas. Por meio de análise de variância, foram observadas diferenças significativas de dano da geada na folha e no caule entre as espécies (Tabela 2). A espécie Mimosa scabrella se destacou em relação à resistência à geada, ou seja, ela não apresentou danos visíveis tanto na folha como no caule, logo, teve $100 \%$ de sobrevivência (Tabela 3), demonstrando ser uma espécie resistente

Tabela 2 - Resumo da análise de variância para o dano na folha e no caule e porcentagem de sobrevivência após ocorrência de geada, depois de um ano de plantio das quatro espécies florestais Acacia mearnsii, Eucalyptus grandis, Mimosa scabrella e Ateleia glazioveana, submetidas nos quatro níveis de espaçamentos: $2,0 \times 1,0 \mathrm{~m} ; \quad 2,0 \times 1,5 \mathrm{~m} ; 3,0 \times 1,0 \mathrm{~m}$ e $3,0 \times 1,5 \mathrm{~m}$ no município de Frederico Westphalen - RS.

\begin{tabular}{|c|c|c|}
\hline Fator de estudo & $\begin{array}{l}\text { Grau de } \\
\text { liberdade }\end{array}$ & Quadrado médio \\
\hline \multicolumn{3}{|c|}{----------------------------Dano na folha-------------------------- } \\
\hline Espécie & 2 & $130440,1292 *$ \\
\hline Espaçamento & 3 & $134,2907^{\mathrm{ns}}$ \\
\hline Espécie x Espaçamento & 6 & $98,5192^{\mathrm{ns}}$ \\
\hline Coeficiente de variação (\%) & & 9,22 \\
\hline \multicolumn{3}{|c|}{ - } \\
\hline Espécie & 3 & $1762,2444 *$ \\
\hline Espaçamento & 3 & $3,5880^{\mathrm{ns}}$ \\
\hline Espécie x Espaçamento & 9 & $1,8720^{\mathrm{ns}}$ \\
\hline Coeficiente de Variação (\%) & & 11,82 \\
\hline \multicolumn{3}{|c|}{ - } \\
\hline Espécie & 3 & $504,0144^{*}$ \\
\hline Espaçamento & 3 & $17,1433^{\mathrm{ns}}$ \\
\hline Espécie x Espaçamento & 9 & $17,1433^{\text {ns }}$ \\
\hline Coeficiente de variação (\%) & & 10,09 \\
\hline
\end{tabular}

$*$ = Significativo a $5 \%$ de probabilidade de erro. ns = não significativo.

Ciência Rural, v.41, n.5, mai, 2011. 
(Tabela 4). Resultados semelhantes foram encontrados pelos autores CARVALHO \& COSTA (1981) avaliando o comportamento silvicultural de espécies florestais em condições de arboreto aos 39 meses após o plantio, em quatro locais do Paraná, onde constataram a grande resistência à geada desta espécie.

A Mimosa scabrella é uma espécie que não é, generalizadamente, tolerante às geadas. Resultados diferentes dos observados pelos autores foram relatados por CARVALHO (2003) em que, bracatingais com menos de um ano, após sofrer geadas severas, apresentaram-se totalmente ou parcialmente queimadas. De acordo com o mesmo autor, no sul do Brasil, plantios realizados após março podem ser afetados por geadas precoces. Para se evitar danos por geadas severas no primeiro ano, os plantios devem ser feitos na primavera. $\mathrm{O}$ plantio do experimento no mês de setembro pode ter contribuído para o resultado observado.

O Eucalyptus grandis teve seu dano concentrado nas folhas, demonstrando ser tolerante à geada (Tabela 4). Mais de $93 \%$ das plantas avaliadas apresentaram menos de $25 \%$ da área foliar danificada, $5,6 \%$ das plantas apresentaram de $25-49 \%$ da área foliar danificada. Apesar de sofrer danos, apresentou $100 \%$ de sobrevivência (Tabela 3). Essa espécie não diferiu estatisticamente da Mimosa scabrella em relação ao dano no caule, entretanto, mais de $98 \%$ das plantas tiveram as ponteiras dos caules danificadas. Ou seja, houve ocorrência de dano no caule nas partes em que predominavam tecidos de crescimento recente, como o meristema apical. Dessa forma, o comprometimento do meristema apical, segundo KOZLOWSKI et al. (1991) e HIGA et al. (1997), é problemático por bifurcar ou ramificar o eixo principal de crescimento da árvore. No

Tabela 3 - Média para o dano na folha e no caule e porcentagem de sobrevivência após ocorrência de geada, depois de um ano de plantio das quatro espécies florestais Acacia mearnsii, Eucalyptus grandis, Mimosa scabrella e Ateleia glazioveana, submetidas a diferentes níveis de espaçamentos no município de Frederico Westphalen - RS.

\begin{tabular}{|c|c|c|c|}
\hline \multirow{2}{*}{ Espécie } & \multicolumn{2}{|c|}{ Dano } & \multirow{2}{*}{$\begin{array}{c}\% \\
\text { sobrevivência }\end{array}$} \\
\hline & Folha & Caule & \\
\hline Acacia mearnsii & $32,90 \mathrm{c}$ & $3,05 \mathrm{c}$ & $87,04 \mathrm{~b}$ \\
\hline Mimosa scabrella & $100,00 \mathrm{a}$ & $10,0 \mathrm{a}$ & $100 \mathrm{a}$ \\
\hline Eucalyptus grandis & $80,32 \mathrm{~b}$ & $9,88 \mathrm{a}$ & $100 \mathrm{a}$ \\
\hline Ateleia glazioveana & $*$ & $4,00 \mathrm{~b}$ & $100 \mathrm{a}$ \\
\hline
\end{tabular}

Médias seguidas por letras distintas na coluna diferem entre si pelo teste de Tukey a 5\% de probabilidade de erro.

*= não avaliado.
Tabela 4 - Grau de resistência das quatro espécies florestais Acacia mearnsii, Eucalyptus grandis, Mimosa scabrella e Ateleia glazioveana, submetidas a diferentes níveis de espaçamentos, um ano após o plantio no município de Frederico Westphalen - RS.

\begin{tabular}{ll}
\hline Espécie & \multicolumn{1}{c}{ Grau de resistência } \\
\hline Acacia mearnsii & Moderadamente tolerante - tolerante \\
Mimosa scabrella & Resistente \\
Eucalyptus grandis & Tolerante \\
Ateleia glazioveana & Tolerante \\
\hline
\end{tabular}

entanto, HIGA (2000) observou a retomada de crescimento de árvores de eucaliptos em um único eixo principal, demonstrando a capacidade de recuperação dessa espécie.

Apresentando similaridade ao experimento, HIGA et al. (2000), avaliando danos causados por geada em progênies de Eucalyptus dunnii Maiden, em Campo do Tenente, PR, também pelo sistema de notas, um mês após a ocorrência de geada, observaram que todas as plantas apresentaram danos visíveis, sendo que 4,76\% das plantas foram totalmente queimadas pela geada, sendo observada temperatura de $-6,5^{\circ} \mathrm{C}$ na ocorrência da primeira geada. No entanto, nove meses após as geadas, 3,87\% das plantas não apresentaram nenhum sinal de danos, sendo que somente $2,38 \%$ confirmaram a nota zero, recebida logo após a geada. Dessa forma, temperaturas abaixo ou próximas de $0^{\circ} \mathrm{C}$ (medidas em abrigo meteorológico), ocasionam danos em eucaliptos, resultando desde a perda da área foliar até a morte das plantas (PALUDZYSZYN FILHO \& SANTOS, 2005).

Em $100 \%$ das plantas de Ateleia glazioveana, o dano foi localizado em menos de $25 \%$ do caule, caracterizando-se ser uma espécie tolerante à geada (Tabela 4), apresentando $100 \%$ de sobrevivência (Tabela 3). Resultados semelhantes foram encontrados por CARVALHO (2003), destacando que essa espécie suporta entre 0 a 30 geadas por ano, sendo a temperatura do mês mais frio de $-10,4^{\circ} \mathrm{C}$.

A Acacia mearnsii foi a espécie mais susceptível aos danos da geada tanto na folha como no caule, demonstrando ser uma espécie que varia de moderadamente tolerante a tolerante à geada (Tabela 4). Mais de $60 \%$ das plantas tiveram $100 \%$ da área foliar danificada e mais de $31 \%$ apresentaram entre 75 a $99 \%$ de dano. Mais de $20 \%$ das plantas apresentaram no caule entre 75 a $99 \%$ de dano. Pouco mais de $16 \%$ entre 50 a $75 \%, 26 \%$ entre 25 a $49 \%$ e mais de $33 \%$ apresentaram menos de $25 \%$ de dano. Somente em $3 \%$ das plantas não foram observados danos visíveis no caule. Como era de se esperar a partir dos danos observados, foi a única espécie que apresentou 
mortalidade, sendo a sobrevivência das plantas após 100 dias da ocorrência da última geada de $84,04 \%$ (Tabela 3).

As diferentes intensidades de dano encontradas pelos autores no trabalho podem ser explicadas pela maior resistência de algumas plantas às geadas (HIGA, 2000). Da mesma forma, VIEIRA et al. (2003) e HALL et al. (1970) destacaram que a diferença da capacidade de tolerância à geada, assim como a queima de tecidos da planta pode estar associada às diferenças fisiológicas, morfológicas e genéticas existentes entre as espécies e até dentro de uma mesma espécie. Assim, esta é uma explicação ao fato da variabilidade entre as espécies em relação à resistência a geadas encontradas no experimento, e pelos níveis de espaçamento estudados não terem alterado respostas das espécies florestais ao dano ocasionado por geada. Nesse sentido, HIGA (2000) demonstrou o potencial de melhoramento genético da Acacia mearnsii para esta característica, apresentando valores altos de coeficiente de herdabilidade em relação à resistência à geada, em nível de indivíduos ou até de família.

\section{CONCLUSÃO}

A espécie Mimosa scabrella não sofreu danos de geada, caracterizando-se como resistente. As espécies Eucalyptus grandis e Ateleia glazioveana, em função dos seus pequenos danos observados, demonstraram-se tolerantes. A Acacia mearnsii apresenta-se ser moderadamente tolerante a tolerante, característica dada pelas diferenças de comportamento entre as plantas.

Os níveis de espaçamento estudados não alteraram respostas das espécies florestais analisadas, em relação ao dano ocasionado por geada.

\section{REFERÊNCIAS}

ARAÚJO, L.C. Memórias sobre o clima do Rio Grande do Sul. Rio de Janeiro: Ministério da Agricultura, Indústria e Comércio, 1930. 101p.

CAMARGO, M.B.P. et al. Probabilidade de ocorrência de temperaturas mínimas absolutas mensais e anuais no Estado de São Paulo. Bracatinga, Campinas, v.52, n.2, p.161168, 1993. Disponível em: <http://www.scielo.br/ scielo.php?script=sci_arttext\&pid=S 0006 $87051993000200008 \& \operatorname{lng}=\mathrm{en} \& \mathrm{nrm}=\mathrm{i}$ so \& $\mathrm{t} \operatorname{lng}=\mathrm{pt}>$. Acesso em: 20 jan. 2010. doi: 10.1590/S000687051993000200008 .

CARVALHO, P.E.R. Competição entre espécies florestais nativas em Irati - PR, cinco anos após o plantio. Boletim de Pesquisa Florestal, Colombo, n.2, p.41-56, 1981.
CARVALHO, P.E.R. Espécies arbóreas brasileiras. Brasília: Embrapa informação tecnológica; Colombo - PR: Embrapa Florestas, 2003. V.1, 1039p.

CARVALHO, P.E.R.; COSTA, J.M. Comportamento de essências florestais em condições de arboreto em quatro locais do Estado do Paraná. In: SEMINÁRIO SOBRE ATUALIDADES E PERSPECTIVAS FLORESTAIS - "Bracatinga uma alternativa para reflorestamento", 4., 1981, Curitiba, PR. Anais... Curitiba: EMBRAPA/URPFCS, 1981. V.1, 198p.

FLOSS, P.A. et al. Teste de procedências e progênies de Eucalyptus viminalis Labill na Região Oeste de Santa CatarinaBrasil, 1997. In: IUFRO Conference on Silviculture and Improvement of Eucalypts, 1997, Salvador, BA. Anais... Colombo: EMBRAPA, 1997. V.4.

GRODZKI, L. et al. Riscos de geada no estado do Paraná. Revista Brasileira de Agrometeorologia, Santa Maria, v.4, n.1, p.93-99, 1996. Disponível em: <http://www.scielo.br/ scieloOrg/ph p/reflinks.php?refpid=S 0100 $2945200800040003300010 \& \mathrm{pid}=\mathrm{S} 0100$ $29452008000400033 \& \operatorname{lng}=\mathrm{em}>$. Acesso em: 18 out. 2009.

HALL, N. et al. Forest trees of Australia. Department of National Development - Forestry and Timber Bureau. Canberra: Australian Government Publishing Service, 1970. 72p.

HIGA, R.C.V. et al. Comportamento de vinte espécies de Eucalyptus em área de ocorrência de geadas na região sul do Brasil. 1997. In: IUFRO Conference on Silviculture and Improvement of Eucalypts, 1997, Salvador, BA. Anais... Colombo: EMBRAPA, 1997. V.4.

HIGA, R.C.V. et al. Resistência e resiliência a geadas em Eucalyptus dunnii Maiden Plantados em Campo do Tenente, PR. Boletim de Pesquisa Florestal, Colombo, n. 40, p.67$76,2000$.

INMET. Instituto Nacional de Meteorologia. Casos significativos do mês de julho de 2007. Disponível em: <http://www.cptec.inpe.br/ promet/figcartas/resum_mensal/ jul07/cas_sig_jul07.pdf>. Online. Acesso em: 08 de out. 2010.

KOZLOWSKI, T.T. et al. The physiological ecology of woody plants. San Diego: Academic, 1991. 657p.

MALUF, J.R.T. Nova classificação climática do Estado do Rio Grande do Sul. Revista Brasileira de Agrometeorologia, Santa Maria, v.8, n.1, p.141-150, 2000. Disponível em: <http:/ /www.ufsm.br/rba/p14181.html>. Acesso em: 12 fev. 2010.

MOTA, F.S. Meteorologia agrícola. São Paulo: Nobel, 1975. $376 \mathrm{p}$.

PALUDZYSZYN FILHO, E.; SANTOS, P.E.T. Considerações sobre o plantio de Eucalyptus dunnii, no estado do Paraná. Colombo-PR: EMBRAPA, 2005. 7p. (Comunicado Técnico, 141).

PEREIRA, A.R. et al. Agrometeorologia: fundamentos e aplicações práticas. Guaíba: Agropecuária, 2001. 478p.

PILAU, F.G. et al. Radiation balance of an orange tree in orchard and its relation with global solar radiation and grass net radiation. Revista Brasileira de Agrometeorologia, Santa Maria, v.15, n.3, p.257-266, 2007. Disponível em: <http:// 
www.sbagro. org.br/rbagro/ojs/index.php/rbagro/article/viewFile/ 66/17>. Acesso em: 18 dez. 2009.

SAS LEARNING EDITION. Getting started with the SAS Learning Edition. Cary, 2003. 200p.

SELLE, G.L.; VUADEN, E. Comunicação: efeitos da geada sobre plantações de Eucalyptus grandis. Caderno de pesquisa, série Biologia, Santa Cruz do Sul, v.20, p.36-45, 2007.

SILVA, J.G.; SENTELHAS, P.C. Diferença entre temperatura mínima do ar medida no abrigo e na relva e probabilidade de sua ocorrência em eventos de geadas no Estado de Santa Catarina.
Revista Brasileira de Agrometeorologia, Santa Maria, v.9, n.1, p.9-15, 2001. Disponível em: <http://www.scielo.br/ scieloOrg/php/reflinks.php?refpid=S0006-870520050 $0010001500017 \& \mathrm{pid}=$ S0006-87052005000100015\&lng=en>. Acesso em: 10 mar. 2010.

VIEIRA, A.R.R. et al. Adaptação de espécies arbóreas nativas em um sistema agrossilvipastoril, submetidas a extremos climáticos de geada na região de Florianópolis. Revista Árvore, Viçosa, v.27, n.5, p.627-634, 2003. Disponível em: <http:// www.scielo.br/scielo.php? script $=$ sci_arttext\&pid $=S 0100$ $67622003000500005 \& \operatorname{lng}=$ pt\&nrm=iso $>$. Acesso em: 20 jun. 2010. doi: 10.1590/S0100-67622003000500005. 